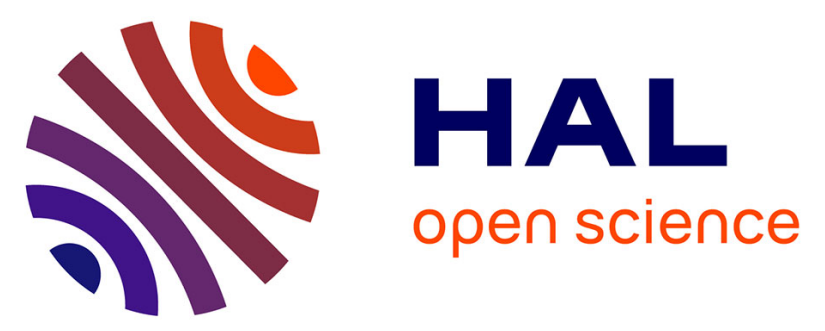

\title{
Magnetic Fe@Y Composites as Efficient Recoverable Catalysts for the Valorization of the Recalcitrant Marine Sulfated Polysaccharide Ulvan
}

Jan Přech, Efstathia Ioannou, Vassilios Roussis, Victor Kuncser, Iunia Podolean, Simona Margareta Coman, Valentin Valtchev, Vasile I Parvulescu

\section{To cite this version:}

Jan Přech, Efstathia Ioannou, Vassilios Roussis, Victor Kuncser, Iunia Podolean, et al.. Magnetic Fe@Y Composites as Efficient Recoverable Catalysts for the Valorization of the Recalcitrant Marine Sulfated Polysaccharide Ulvan. ACS Sustainable Chemistry \& Engineering, 2019, 8 (1), pp.319-328. 10.1021/acssuschemeng.9b05406 . hal-03035150

HAL Id: hal-03035150

https://hal-normandie-univ.archives-ouvertes.fr/hal-03035150

Submitted on 3 Dec 2020

HAL is a multi-disciplinary open access archive for the deposit and dissemination of scientific research documents, whether they are published or not. The documents may come from teaching and research institutions in France or abroad, or from public or private research centers.
L'archive ouverte pluridisciplinaire HAL, est destinée au dépôt et à la diffusion de documents scientifiques de niveau recherche, publiés ou non, émanant des établissements d'enseignement et de recherche français ou étrangers, des laboratoires publics ou privés. 


\title{
Magnetic Fe@Y composites as efficient recoverable
}

\section{catalysts for the valorization of recalcitrant biomass}

\author{
Jan Přech,,$^{\dagger}$ Estathia Ioannou, ${ }^{*}$ Vassilios Roussis, ${ }^{* \neq}$ Victor Kuncser, ${ }^{\S}$ Iunia Podolean, ${ }^{\perp}$ \\ Simona M. Coman, ${ }^{\perp}$ Valentin Valtchev, ${ }^{* \dagger},\|\|$ and Vasile I. Parvulescu ${ }^{* \perp}$
}

${ }^{\dagger}$ Normandie Univ, ENSICAEN, UNICAEN, CNRS, Laboratoire Catalyse et Spectrochimie, 6 Marechal Juin, 14050 Caen, France

$\ddagger$ Department of Pharmacognosy and Chemistry of Natural Products, Faculty of Pharmacy, National and Kapodistrian University of Athens, Panepistimiopolis Zografou, Athens 15771, Greece

${ }^{\S}$ National Institute of Materials Physics, Atomistilor 105b, 077125 Magurele-Ilfov, Romania

${ }^{\perp}$ Department of Organic Chemistry, Biochemistry and Catalysis, Faculty of Chemistry, University of Bucharest, Bdul Regina Elisabeta 4-12, Bucharest 030016, Romania

॥ State Key Laboratory of Inorganic Synthesis and Preparative Chemistry, Jilin University, Changchun 130012, P. R. China

KEYWORDS: Y zeolite, magnetic nanoparticles, ulvan, hydrolysis, oxidation 


\begin{abstract}
Magnetic Fe@Y composites (carbon coated magnetic iron nanoparticles incorporated in Y zeolite) with 5-8 wt $\%$ Fe were synthesized and characterized. Overall acidity of the samples ranges between 2.0 and $2.47 \mathrm{mmol} / \mathrm{g}$ and is given mostly by Lewis acid sites. The obtained materials were proven to catalyze the hydrolysis of Ulvan polysaccharide with high conversions. The distribution of the reaction products depends on the reaction conditions and the concentration of Ulvan. The catalytic properties - catalytic performances correlations clearly show the acid zeolite $\mathrm{Y}$ is the active phase for Ulvan hydrolysis while the iron nanoparticles enable the catalyst separation in a magnetic field. Under oxygen pressure, the selectivity was completely changed to succinic acid. All Fe@Y composites were recycled for 10 times with no change in the catalytic performances after a simple magnetic separation and washing with water.
\end{abstract}

\title{
INTRODUCTION
}

The research interest in the area of biomass valorization continues to grow due to the daily increased need in commodity chemicals and the necessity to replace the petroleum feedstock until it will become economically infeasible. Among the different groups of biomass, marine biomass deserves particular attention. Algal biomass represents an important source of lipids, proteins and carbohydrates. For instance, in the case of green algae, after the extraction of lipids, the residue contains constituents of cell-walls such as water soluble Ulvan and insoluble cellulose. However, although sulfated polysaccharides from Ulvan can be catalytically converted to valuable monomers or other products, the literature reports are scarcely in this area. ${ }^{1,2}$

The Ulvan structure is, to some extent, similar to that of hemicelluloses. ${ }^{3}$ It corresponds to a mixture of pentoses, hexoses (glucose, galactose, and mannose) and hexuronic acids 
(galacturonic and glucuronic acid). A common structure unit is descripted as glucose, xylose or mannose bounded via $\alpha-1,4$ glycosidic bonds. Its main constituents are residues of sulfated rhamnose linked to uronic acids (glucuronic or iduronic acids) resulting in repeated disaccharide $\beta$-D-glucuronosyl-(1,4)- $\alpha$-L-rhamnose-3-sulfate units. ${ }^{4}$

Catalytic materials are important tools to valorize the marine biomass, and their design, in direct relation to the complexity of the renewable biomass continues to be an important challenge. The advantages of the solid materials as heterogeneous catalysts are un-doubtful since both the feedstock and the products are cheap; accordingly, the catalysts should be stable and completely recoverable. Zeolites represent a class of catalysts characterized by an excellent thermal and chemical stability, by versatility and shape selectivity. Today, there are many examples of successful applications of zeolites in terrestrial biomass conversion to valuable chemicals. ${ }^{5}$ The hydrolysis of polysaccharides (sucrose) over microporous zeolites follows the following rate trend FER $<$ MOR $\sim$ MFI $<$ BEA $\sim$ MWW $<$ FAU, increasing with zeolite accessibility and acidity. ${ }^{6}$ A similar trend was evidenced by the hydrolysis of inulin ${ }^{7}$ in which zeolites with meso-/microporosity displayed higher activity than the microporous ones. However, to-date, studies on the behavior of zeolites in the algal Ulvan hydrolysis is only tangential. ${ }^{1,2}$

The separation of the solid catalysts from the reaction mixtures such as those resulting from the processing of large molecules in viscous or solid reaction mixtures, also characteristic to the biomass valorization, requires forceful energy-intensive steps, making the process more complex and expensive. To overcome these concerns, the use of solid magnetic catalysts allows an efficient separation from the reaction mixture by applying an external magnetic field. Such an approach is not affecting the catalytic behavior. ${ }^{8,9}$ In this context, literature already reported 
encapsulated magnetite microspheres in zeolite $\beta^{10}$ and ZSM-5 for the valorization of cellulosic fragments. $^{11}$

Taking into account the above considerations and the high scientific and economic interest in the development of new efficient magnetic-based solid catalysts for the biomass valorization, here we report the synthesis of carbon coated magnetic nanoparticles, incorporated in zeolite and its use for the hydrolysis of Ulvan polysaccharide extracted from Ulva rigida algae.

\section{EXPERIMENTAL SECTION}

1. Catalysts preparation. 1.1. Synthesis of carbon coated iron nanoparticles. The iron nanoparticles were prepared using a modified microemulsion method ${ }^{12}$ in the following way: $3 \mathrm{~g}$ of cetyltrimethylammonium bromide (CTAB, $98 \%$, Sigma-Aldrich), $5 \mathrm{~g}$ of 1-hexanol (98\%, Sigma-Aldrich) and $2 \mathrm{~g}$ of aqueous solution of $\mathrm{Fe}\left(\mathrm{NO}_{3}\right)_{3}\left(0.5 \mathrm{~mol} / \mathrm{l} ; \mathrm{Fe}\left(\mathrm{NO}_{3}\right)_{3} \cdot 9 \mathrm{H} 2 \mathrm{O}, 99.95 \%\right.$ Sigma-Aldrich) were combined and stirred vigorously for $30 \mathrm{~min}$ on a magnetic stirrer at room temperature to form emulsion I. The $\mathrm{pH}$ of the aqueous part of the emulsion was then adjusted to $\mathrm{pH}=10$ by adding 15 drops of $28 \% \mathrm{NH}_{4} \mathrm{OH}$ solution (Alfa Aesar) to precipitate $\mathrm{Fe}(\mathrm{OH})_{3}$ nanoparticles. After stirring for another $30 \mathrm{~min}$, the emulsion I was combined with an emulsion II. The emulsion II was prepared from $3 \mathrm{~g}$ of CTAB, $5 \mathrm{~g}$ of 1-hexanol and $2 \mathrm{~g}$ of aqueous solution of glucose $(99.8 \%$, Fisher Scientific). The glucose concentration was $0.1 \mathrm{~mol} / 1$ for 6wt $\% \mathrm{Fe} @ \mathrm{Y}$ and $0.2 \mathrm{~mol} / 1$ for $8 \mathrm{wt} \% \mathrm{Fe} @ \mathrm{Y}$. In the case of $5 \mathrm{wt} \% \mathrm{Fe} @ \mathrm{Y}, 2 \mathrm{~g}$ of $0.2 \mathrm{~mol} / 1$ glucose solution were added directly into emulsion I (instead of introducing the glucose solution via emulsion II). The combined emulsions were stirred for $1 \mathrm{~h}$ and then transferred into a Teflon lined autoclave and subjected to hydrothermal treatment under static conditions at $130^{\circ} \mathrm{C}$ for 62 h. After the given time, resulting carbon coated iron oxide nanoparticles were filtered on a 
membrane $(0.45 \mu \mathrm{m}$ pores $)$, washed with ethanol $(100 \mathrm{~mL})$, ethanol/water 1:1 mixture $(100 \mathrm{~mL})$ and distilled water $(100 \mathrm{~mL})$. While making the 6wt\%Fe@Y sample, the nanoparticles were dried while in the cases of $8 \mathrm{wt} \% \mathrm{Fe} @ \mathrm{Y}, 5 \mathrm{wt} \% \mathrm{Fe} @ \mathrm{Y}$ they were kept as a wet cake until the introduction to the zeolite synthesis gel. The dry nanoparticles $(56 \mathrm{mg}$ isolated and used while preparing the $6 \mathrm{wt} \% \mathrm{Fe} @ \mathrm{Y}$ batch) reacted to a magnet.

1.2. Synthesis of Fe@Y composites. The Fe@Y composite catalysts were prepared by the incorporation of carbon coated iron oxide nanoparticles into zeolite Y. The zeolite Y synthesis gel was prepared following the method reported in Ref. 13: $2.49 \mathrm{~g}$ of water, $0.509 \mathrm{~g}$ of $\mathrm{NaOH}$ (99 \%, VWR Chemicals) and $0.261 \mathrm{~g}$ of $\mathrm{NaAlO}_{2}$ (technical, anhydrous, Sigma-Aldrich) were stirred until a clear solution was obtained. Then 2.84 of sodium silicate solution (reagent grade, Sigma-Aldrich) was added, stirred for about $1 \mathrm{~h}$ and left to age statically at room temperature for $24 \mathrm{~h}$ to form seeding gel I. Similarly, a feedstock gel II was prepared from $16.37 \mathrm{~g}$ of water, $0.0175 \mathrm{~g}$ of $\mathrm{NaOH}, 1.74 \mathrm{~g}$ of $\mathrm{NaAlO}_{2}$ and after dissolution $17.80 \mathrm{~g}$ of sodium silicate solution. The gel II was very dense and therefore needed to be stirred mechanically.

In the case of $6 \mathrm{wt} \% \mathrm{Fe} @ \mathrm{Y}, 53 \mathrm{mg}$ of dry nanoparticles, $631 \mathrm{mg}$ of seeding gel I and $3.60 \mathrm{~g}$ of feedstock gel II were mixed together, stirred vigorously for $5 \mathrm{~min}$, aged statically overnight and subjected to the hydrothermal synthesis in a polypropylene bottle under static conditions at $100^{\circ} \mathrm{C}$ for $6.5 \mathrm{~h}$. After the given time, the solid product was filtered, washed with copious amount of water and dried at room temperature.

For the $8 \mathrm{wt} \% \mathrm{Fe} @ \mathrm{Y}$ and 5wt\%Fe@Y, $3.38 \mathrm{~g}$ of wet nanoparticles suspension (corresponding to about $440 \mathrm{mg}$ of dry nanoparticles) were mixed with $3.39 \mathrm{~g}$ of seeding gel I and $19.09 \mathrm{~g}$ of feedstock gel I each, homogenized for $15 \mathrm{~min}$, aged for $2 \mathrm{~h}$ at room temperature and the 
crystallization occurred at $90^{\circ} \mathrm{C}$ for $22 \mathrm{~h}$. After the synthesis, the samples were recovered as reported for 6wt\%Fe@Y.

The crude iron oxide@Y composites were reduced in a flow of hydrogen $(100 \mathrm{ml} / \mathrm{min})$ at $400^{\circ} \mathrm{C}$ for $16 \mathrm{~h}$ in a slowly rotating furnace. The temperature ramp was $2^{\circ} \mathrm{C} / \mathrm{min}$. Resulting Fe@Y composites were converted into $\mathrm{NH}_{4}{ }^{+}$form by 4 treatments in $1 \mathrm{~mol} / 1 \mathrm{NH}_{4} \mathrm{NO}_{3}$ aqueous solution $(100 \mathrm{ml} / \mathrm{g}$ of zeolite, $4 \mathrm{~h}$ each treatment).

2. Catalysts characterization. X-ray powder diffraction patterns (XRD) were collected on a PAN analytical X'Pert PRO diffractometer using CuKa radiation in Bragg-Brentano geometry. Data were collected in continuous mode over the $2 \theta$ range of $5-50^{\circ}$.

The size and shape of zeolite crystals were investigated by scanning electron microscopy (SEM) on a MIRA TESCAN microscope equipped with a field emission gun. The images were collected with an acceleration voltage of $30 \mathrm{kV}$.

Nitrogen sorption isotherms were measured at liquid nitrogen temperature $\left(-196^{\circ} \mathrm{C}\right)$ with a Micromeritics 3Flex volumetric instrument. Prior to the sorption measurements, samples were outgassed under a turbomolecular pump vacuum $\left(\mathrm{p}_{\min }=1.10^{-6}\right.$ torr) at $300^{\circ} \mathrm{C}$ for $6 \mathrm{~h}$. The data were collected in range $\mathrm{p} / \mathrm{p}_{0}=1.1 \cdot 10^{-7}-0.97$. BET area was evaluated using adsorption data in the range of a relative pressure from $\mathrm{p} / \mathrm{p}_{0}=1.1 \cdot 10^{-7}$ to $\mathrm{p} / \mathrm{p}_{0}=0.01$ (corresponding to the growing part of Rouquerol BET plot). The t-plot method $^{14}$ using Harkins-Jura thickness equation was applied to determine the external surface area $\left(\mathrm{S}_{\mathrm{ext}}\right)$. Micropore volume $\left(\mathrm{V}_{\text {mic }}\right)$ was determined from NLDFT based pore size analysis using a model for $\mathrm{N}_{2}$ at $-196^{\circ} \mathrm{C}$ on oxide surface with cylindrical pore geometry (part of the Micromeritics user software). The NLDFT based pore size analysis was used because it is more accurate in comparison with the t-plot method. The t-plot method underestimates the $\mathrm{V}_{\text {mic }}$ due to the curvature effect (the t-plot uses flat surface reference 
isotherm, which is far from the reality in zeolite micropores). The adsorbed amount of nitrogen at $\mathrm{p} / \mathrm{p}_{0}=0.95$ reflects the total pore volume $\left(\mathrm{V}_{\text {total }}\right)$.

Elemental analysis was performed using an ICP-OES. Samples were dissolved in a mixture of HF and Aqua Regia before the analysis.

Acidic properties were determined from adsorption/desorption of pyridine (Py) followed by FTIR spectroscopy (Thermo Scientific Nicolet 6700 FT-IR). The individual samples were pressed into self-supporting wafers with a density of $8.0-12 \mathrm{mg} / \mathrm{cm}^{2}$ and activated at $450^{\circ} \mathrm{C}$ for 5 h. Pyridine adsorption was carried out at $150^{\circ} \mathrm{C}$ for $30 \mathrm{~min}$ at partial pressure 1 torr, followed by sequential desorption for $15 \mathrm{~min}$ at different temperatures $\left(150,250,350,450^{\circ} \mathrm{C}\right)$ to estimate the strength of acid sites. The concentration of acid sites in Table 3.1 was determined after desorption at $150^{\circ} \mathrm{C}$. All spectra were recorded with a resolution of $4 \mathrm{~cm}^{-1}$ by collecting 128 scans for a single spectrum. Spectra were recalculated to a wafer density of $10 \mathrm{mg} / \mathrm{cm}^{2}$. Concentrations of Lewis $(\mathrm{c}(\mathrm{L}))$ and Brønsted (c(B)) acid sites were determined from integral intensities of bands at $1454 \mathrm{~cm}^{-1}$ (Lewis) and at $1545 \mathrm{~cm}^{-1}$ (Brønsted acid sites) using extinction coefficients, $\varepsilon(\mathrm{L})=0.89 \mathrm{~cm} / \mu \mathrm{mol},{ }^{15}$ and $\varepsilon(\mathrm{B})=1.36 \mathrm{~cm} / \mu \mathrm{mol} .{ }^{16}$

3. Ulvan extraction and characterization. Ulvan material was extracted from Ulva rigida algal specimen collected in Nafplion bay, Greece, in July 2015. Ulvan was extracted from dried alga in hot water. The polysaccharides precipitation has been achieved by the addition of 4 volumes of $96 \%(\mathrm{v} / \mathrm{v})$ ethanol and subsequent storage at $4{ }^{\circ} \mathrm{C}$. Dried Ulvan was exhaustively analyzed using the set of methods reported in Table 1 .

Table 1. Characterization methods of Ulvan.

\begin{tabular}{lll}
\hline Compound & Method & Reference \\
\hline
\end{tabular}




\begin{tabular}{lll}
\hline Proteins & Micro-Kjeldahl method $(\mathrm{N} \times 6.25)$ & \\
Ash & Gravimetrically after incineration $\left(550{ }^{\circ} \mathrm{C}\right.$ for $16 \mathrm{~h}$ and 2 & \\
& $\mathrm{h}$ at $\left.900{ }^{\circ} \mathrm{C}\right)$ & 17 \\
Total sugars & Colorimetrically (phenol-sulfuric method) & 18 \\
Uronic acid & $m$-Hydroxydiphenyl method & 19 \\
Neutral sugars & Hydrolysis in trifluoroacetic acid & 20 \\
Monosaccharides & GC-MS & 21 \\
Sulfates &
\end{tabular}

The molecular weight distribution of Ulvan was determined HPSEC-RI (High Pressure Size Exclusion Chromatography coupled with Refractive Index detection), using a LKB 2248 pump equipped with a Shodex RI-10 detector and a BIO BASIC SEC-1000 (Thermo Scientific, 300 $\mathrm{mm} \times 7.8 \mathrm{~mm})$.

4. Ulvan hydrolysis and product analysis. Catalytic hydrolysis of Ulvan was performed into a high pressure stainless steel autoclave with a glass liner. Usually, $20 \mathrm{mg}$ of catalyst were added to aqueous slurry of Ulvan powder $(50 \mathrm{mg}$ in $5 \mathrm{~mL}$ deionized water, corresponding to an Ulvan concentration of $5.9 \times 10^{-3} \mathrm{M}$ ). The mixture was kept at $180{ }^{\circ} \mathrm{C}$ for $6 \mathrm{~h}$. After $6 \mathrm{~h}$ the autoclave was cooled, the catalyst was removed by approaching a magnet to the vessel wall and ethanol was added to the liquid phase in a water/ethanol ratio of $1 / 4(\mathrm{v} / \mathrm{v})$. The precipitated untrasformed Ulvan was then separated through filtration, and the solvent (i.e., an aqueous solution of ethanol) was evacuated at $80{ }^{\circ} \mathrm{C}$, under vacuum. The recovered solids (i.e., catalyst and untransformed Ulvan) were dried and weighted. The separated reaction products were sylilated, prior to GC-MS analysis, with BSTFA+TMCS 99:1 (N,O-Bis(trimethylsilyl)trifluoroacetamide, trimethylchlorosilane) in the presence of a small amount of pyridine, as a solvent. The utilized GC-MS equipment was a THERMO Electron Corporation instrument with TG-5SilMS column 
$30 \mathrm{~m} \times 0.25 \mathrm{~mm} \times 0.25 \mu \mathrm{m}$. To assess the yield of the obtained monomers in the liquid phase, the total sugar content was also determined in the initial sample before hydrolysis. For this purpose a similar methylation procedure reported for the analysis of ulvan structure ${ }^{20}$ was used with the difference that the produced methyl glycosides were previously sylilated as described above. Only traces of degradation products were identified in the chromatographic analysis suggesting that methylation did not lead to an advanced degradation of the resulted monomers.

The conversion of Ulvan (Xulvan) was determined based on the weight difference of dried ulvan before and after the reaction. The amount of the catalyst was subtracted from the recovered untransformed ulvan:

$$
X_{\text {ulvan }}(\%)=\left[1-\frac{\left(m_{\text {unreactedulvan }}-m_{\text {catalyst }}\right)}{m_{\text {charged ulvan }}}\right] x 100
$$

The concentration of the most important monomers was estimated through calibration curves of commercial standards at different concentrations. The total concentration of the monomers in the initial sample allowed calculating the selectivity of the products, which was defined according to the following equation:

$$
S(\%)=\frac{C_{i}^{t}}{C_{i}^{0}} x 100
$$

where $c_{i}^{\prime}$ is the concentration of the $\mathrm{i}$ species at time t, whereas $c_{i}^{0}$ is the total concentration of the i species at time zero (before reaction). It considers all the monomers, oligomers and polysaccharides.

Finally, based on the conversion of Ulvan and the yield of products in the liquid phase ( $\mathrm{Y}_{\text {Liquid }}$, an overall selectivity to liquid phase products has been expressed as carbon efficiency $\left(E_{\mathrm{C}}\right)$ : 


$$
E_{C}=\frac{Y_{\text {liquid }}}{X_{\text {ulvan }}} \times 100
$$

\section{RESULTS AND DISCUSSION}

The magnetic Fe@Y composites were synthesized in three steps. First, microemulsion ${ }^{12}$ was used to create the iron oxide nanoparticles which were subsequently is situ incorporated into the zeolite Y particles during the zeolite crystallization and, at the end, reduced to metallic iron. The iron nanoparticles enable fast catalyst separation in a magnetic field while the acid zeolite $\mathrm{Y}$ is the active phase for Ulvan hydrolysis. In the cited reference, ${ }^{12}$ the metallic (cobalt) nanoparticles were created directly in the microemulsion by reduction with $\mathrm{NaBH}_{4}$; however, in the case of the present composite, iron nanoparticles would dissolve in the highly basic zeolite synthesis mixture. Therefore, $\mathrm{pH}$ of the microemulsion with $\mathrm{Fe}\left(\mathrm{NO}_{3}\right)_{3}$ was adjusted to precipitate $\mathrm{Fe}(\mathrm{OH})_{3}$ nanoparticles $(\mathrm{pH}=10)$ and subsequently the surface of the nanoparticles was protected with a carbon layer. In addition, the carbon coated nanoparticles are expected to behave similarly to carbon hard templates. Note that the Fe nanoparticles do not have the role of catalytically active specie. Three slightly different ways of making the carbon coating were tested (see the experimental part). In all the cases, the carbon shell was made by hydrothermal treatment of the nanoparticles with an aqueous solution of glucose. In the case of 6\%Fe@Y and 8\%Fe@Y, the glucose solution was also introduced in emulsion (not to change the water/1-hexanol ratio) while for 5\% $\mathrm{Fe} @ \mathrm{Y}$, the solution was introduced directly to the emulsion doubling the water/1-hexanol ratio. Also we examined if the glucose concentration will influence the formation and stability of the nanoparticles. In the case of $6 \% \mathrm{Fe} @ \mathrm{Y}, 0.1 \mathrm{M}$ solution of glucose was used while for $8 \% \mathrm{Fe} @ \mathrm{Y}$ the concentration was $0.2 \mathrm{M}$. All the three protocols led to sufficiently stable carbon coated iron oxide nanoparticles, which were reducible to metallic iron nanoparticles after 
incorporation into the zeolite $\mathrm{Y}$ and had the desired properties (macroscopic magnetic properties, no Fe leaching under reaction conditions).

The XRD patterns of all prepared Fe@Y composite catalysts are shown in Figure 1. All samples exhibit the characteristics of the FAU-type zeolite XRD patterns. No indication of the presence of significant amounts of an amorphous phase (baseline elevation between $2 \Theta=15^{\circ}$ $30^{\circ}$ ) was found. The metallic iron was identified by the a-Fe (110) reflection at $2 \theta=44.6^{\circ}$. In the XRD pattern of pure zeolite Y sample (Figure 1, green) this reflection is missing.

Figure 2 depicts the Mossbauer spectra of 6 wt $\% \mathrm{Fe} @ \mathrm{Y}$ catalyst collected at temperatures between 6 and $300 \mathrm{~K}$. All spectra present two components. However, their characteristics differ in the range of temperatures below $50 \mathrm{~K}$ compared to those between 50 and $300 \mathrm{~K}$. Spectra collected below $50 \mathrm{~K}$ are characterized by two sextets, one with broad absorptive lines (blue) and a second with very narrow lines (green). The blue component has been fitted with a hipper-fine field distribution and exhibits the spectral characteristics of iron oxides of magnetite-maghemitetype. This distribution suggests atomic configurations specific to very small nanoparticles (with different surface and volume configurations).

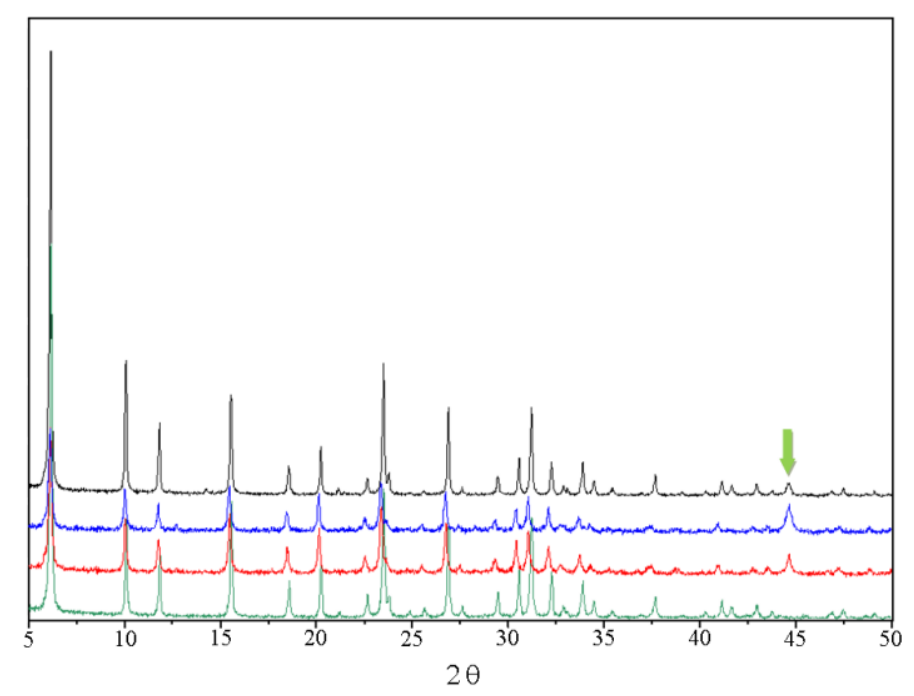


Figure 1. Powder XRD patterns of samples 5 wt\%Fe@Y (red), 6 wt\%Fe@Y (black), 8 wt\%Fe@Y (blue), and pure zeolite Y (green). The arrow marked peak at $44.6^{\circ}$ is the (110) reflection of a-iron.

However, this spectral component rapidly collapses after $50 \mathrm{~K}$, generating a doublet with an isomer shift of aprox $0.4 \mathrm{~mm} / \mathrm{s}$ and a quadrupolar splitting of $0.7(1) \mathrm{mm} / \mathrm{s}$. These values are also specific to $\mathrm{Fe}$ in magnetite/maghemite nanoparticles.

The analysis of the evolution of the hyperfine-field distribution (present on the left-side of the spectra) as a function of the temperature revealed a blocking-temperature at approximately $40 \mathrm{~K}$ which is consistent with dimensions of 3-4 $\mathrm{nm}$. These NPs are super-paramagnetic at room temperature. The analysis of this specific sextet corresponds to a spectral area of approximately $45 \%$. This means that $45 \%$ of iron in this sample exists in this form. However, even at this abundance, dimensions of 3-4 $\mathrm{nm}$ are silent in XRD. 


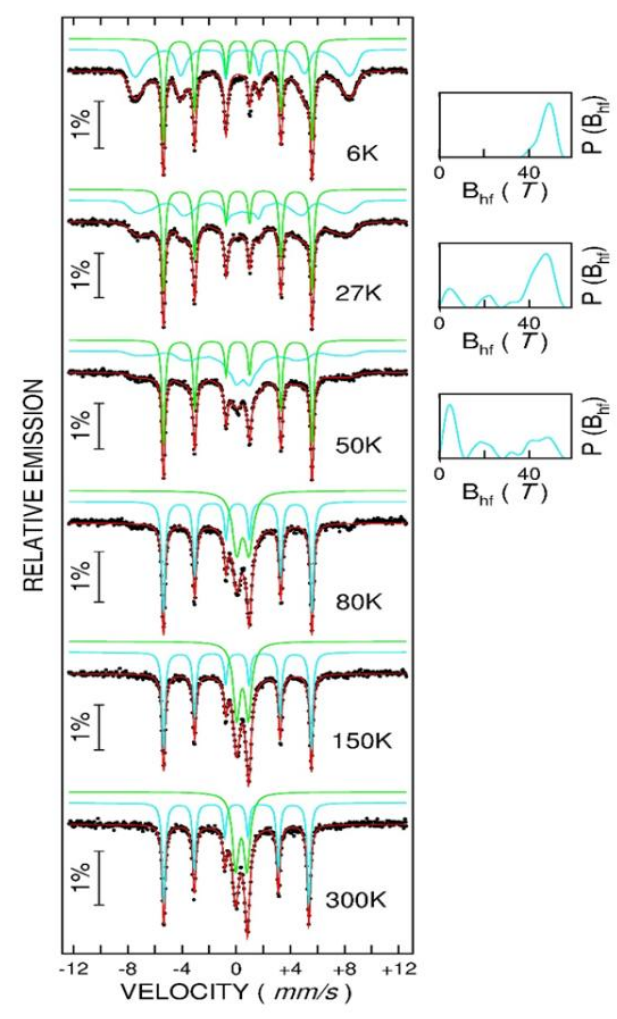

Figure 2. Mossbauer spectra of 6wt $\% \mathrm{Fe} @ Y$ catalyst.

The second component, i.e. the green one, has specific parameters to metallic Fe. The variation of the hiper-fine field with temperature is insignificant (it decreases from $34 \mathrm{~T}$ at $6 \mathrm{~K}$ to $33.2 \mathrm{~T}$ at $300 \mathrm{~K}$ ), that is typical for large particles (over $40-50 \mathrm{~nm}$ ). This is also confirmed by the narrow lines indicating a limited number of metal surface positions and implicitly a large dimension of the particle. These also confirm a net interface between the carbon shell and Fe particles. No lines that can be attributed to iron carbide have been detected. It is worth to mention that $\mathrm{Fe}$ is a magnetic material with a very high magnetization (aprox $500 \mathrm{emu} / \mathrm{g}$, comparative to $90 \mathrm{emu} / \mathrm{g}$ for magnetite) and very small coercive and saturation fields. Accordingly, they are more sensitive to usual magnetic fields (hundreds of Oe). Further thermal treatments generate a collapse of iron oxide nanoparticles leading to large particles visible in the XRD diffractograms and even a slight oxidation of iron nanoparticles. 
The zeolite porosity and the surface areas characterized by nitrogen adsorption measurements are presented in Table 2 and Figure 1S, respectively. Textural properties as well as the shapes of the isotherms correspond to highly crystalline microporous zeolite Y. The surface area for all samples is high, varying between $815-873 \mathrm{~m}^{2} / \mathrm{g}$. External surface areas for $5 \% \mathrm{Fe} @ \mathrm{Y}$ and $8 \% \mathrm{Fe} @ \mathrm{Y}$ are 67 respectively $64 \mathrm{~m}^{2} / \mathrm{g}$, respectively, what is double in comparison with $6 \% \mathrm{Fe} @ \mathrm{Y}\left(\mathrm{S}_{\mathrm{ext}}=33 \mathrm{~m}^{2} / \mathrm{g}\right)$. The total pore volumes for 8\%Fe@Y and 5\%Fe@Y catalysts are 0.41 $\mathrm{cm}^{3} / \mathrm{g}$, whereas 6\%Fe@Y catalyst has a total pore volume of $0.38 \mathrm{~cm}^{3} / \mathrm{g}$.

The iron content is similar in all three samples while in the $6 \% \mathrm{Fe} @ \mathrm{Y}$, the iron particles appears to be the best incorporated inside the crystals (Figure 3). The crystals of $6 \% \mathrm{Fe} @ \mathrm{Y}$ have uniform contrast in SEM images without significant bright spots indicating extra-crystal metallic clusters. In the images of $8 \% \mathrm{Fe} @ \mathrm{Y}$ and 5\%Fe@Y some bright spots can be observed indicating the presence of extra-crystal iron clusters (which are denser and thus brighter that the zeolite phase) or iron clusters intergrown into the zeolite crystals but not fully covered by the zeolitic phase. Based on the observation we can conclude that the synthesis temperature $100^{\circ} \mathrm{C}$ is better for the iron oxide particles incorporation; nevertheless, all the samples exhibited the desired properties (see above).

Table 2. Textural characteristics of the Fe@Y composites

\begin{tabular}{|c|c|c|c|c|c|c|c|c|}
\hline Sample & $\begin{array}{l}\mathrm{BET}^{\lfloor\mathrm{a}\rfloor} \\
\left(\mathrm{m}^{2} / \mathrm{g}\right)\end{array}$ & $\begin{array}{l}V_{\text {mic }}[\mathrm{a}] \\
\left(\mathrm{cm}^{3} / \mathrm{g}\right)\end{array}$ & $\begin{array}{l}V_{\text {tot }}[\mathrm{a}] \\
\left(\mathrm{cm}^{3} / \mathrm{g}\right)\end{array}$ & $\begin{array}{l}\left.\mathrm{S}_{\mathrm{ext}}{ }^{\mathrm{a}}\right\rfloor \\
\left(\mathrm{m}^{2} / \mathrm{g}\right)\end{array}$ & $\begin{array}{l}\mathrm{Si} / \mathrm{Al}^{[\mathrm{b}]} \\
(\mathrm{mol} / \mathrm{mol})\end{array}$ & $\begin{array}{l}\mathrm{Fe}^{[\mathrm{b}]} \\
(\text { wt. } \%)\end{array}$ & $\begin{array}{l}\mathrm{c}(\mathrm{L})^{[\mathrm{c}\rfloor} \\
(\mathrm{mmol} / \mathrm{g})\end{array}$ & $\begin{array}{l}\mathrm{c}(\mathrm{B})^{[\mathrm{c}]} \\
(\mathrm{mmol} / \mathrm{g})\end{array}$ \\
\hline Zeolite Y & 942 & 0.36 & 0.40 & 27 & 1.8 & 0 & n.d. & n.d. \\
\hline 6\%Fe@Y & 873 & 0.33 & 0.38 & 33 & 1.9 & 6.0 & 2.04 & 0.15 \\
\hline 8\%Fe@Y & 815 & 0.30 & 0.41 & 64 & 1.8 & 7.7 & 1.86 & 0.15 \\
\hline 5\%Fe@Y & 828 & 0.31 & 0.41 & 67 & 1.9 & 5.1 & 2.31 & 0.17 \\
\hline
\end{tabular}


[a] Determined from $\mathrm{N}_{2}$ physisorption. [b] Determined by ICP-OES. [c] Determined from pyridine adsorption/desorption at $150^{\circ} \mathrm{C}$.
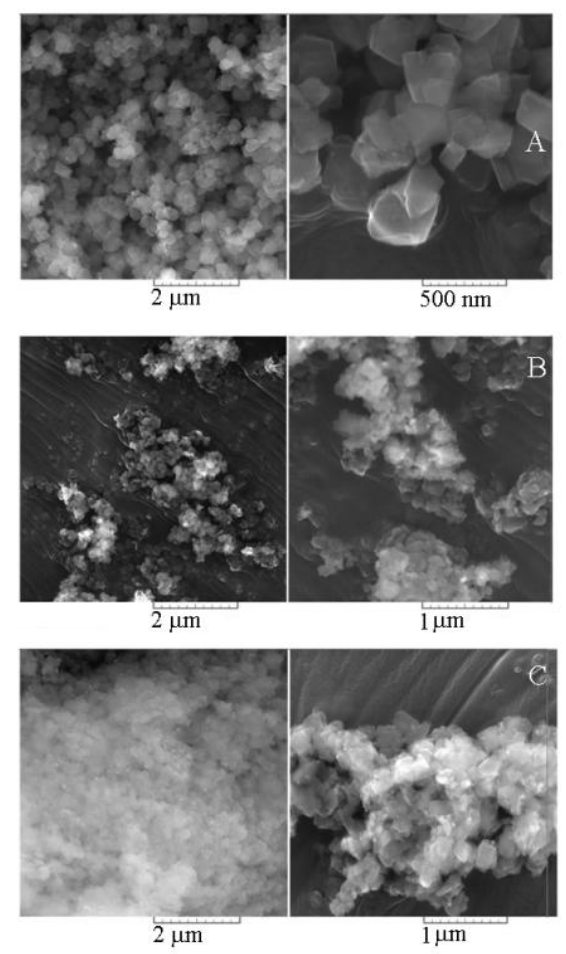

Figure 3. SEM images of $\mathrm{Fe} @ \mathrm{Y}$ composites under different magnification: 6\% $\mathrm{Fe} @ \mathrm{Y}$ (A), 8\%Fe@Y (B) and 5\%Fe@Y (C).

The samples contain mostly Lewis acid sites and only a small fraction, about $7 \%$ of the total amount, are Brønsted acid sites. The overall acidity of the samples is similar ranging between 2.0 and $2.47 \mathrm{mmol} / \mathrm{g}$ of acid sites based on pyridine adsorption/desorption analysis. The strength of the acid sites is compared in Erreur ! Source du renvoi introuvable.4. Difference IR spectra after pyridine desorption at $150^{\circ} \mathrm{C}$ are shown in Erreur ! Source du renvoi introuvable.5. The distribution of the acid sites strength is practically the same for all the samples. That was expected since the composition of the synthesis gel was the same for all 3 samples. The observed slight differences in concentration of the acid sites can be ascribed to the fact that different 
crystallization time and temperature were used $\left(100^{\circ} \mathrm{C}, 6.5 \mathrm{~h}\right.$ for $6 \% \mathrm{Fe} @ \mathrm{Y}$ vs. $90^{\circ} \mathrm{C}, 22 \mathrm{~h}$ for 8\%Fe@Y, 5\%Fe@Y) and the wet cakes of nanoparticles used in syntheses of 8\% $\mathrm{Fe} @ \mathrm{Y}$ and 5\% Fe@Y might have had different composition (e.g. water content).

The analysis of the Ulvan's composition corresponds to $39.2 \%$ carbohydrates, $48.6 \%$ sulfate, and $0.4 \%$ protein on a dry weight basis. The remaining $11.8 \%$ corresponds to ash. Further analysis of carbohydrates corresponds to uronic acids (i.e., glucuronic acid) (17.9\%) and rhamnose (26.3\%). The difference represents other C5-C6 monomeric units as xylose (C5), mannose (C6), galactose (C6), and glucose (C6). The samples had a molecular weight distribution centered on $1.7 \mathrm{kDa}(1.700 \mathrm{~g} / \mathrm{mol})$.

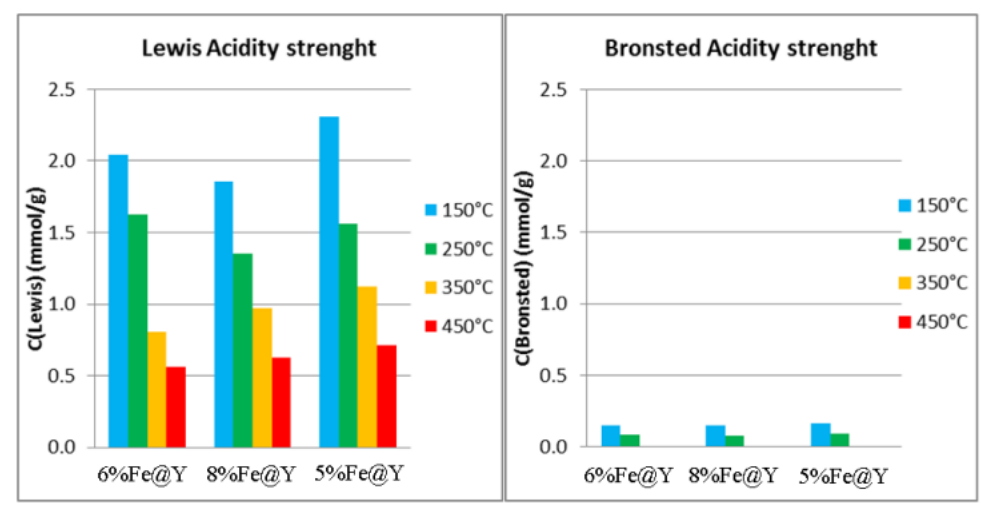

Figure 4. Comparison of acidity strength as number of acid sites (Lewis - left, Bronsted - right) able to bind pyridine at given desorption temperature. 


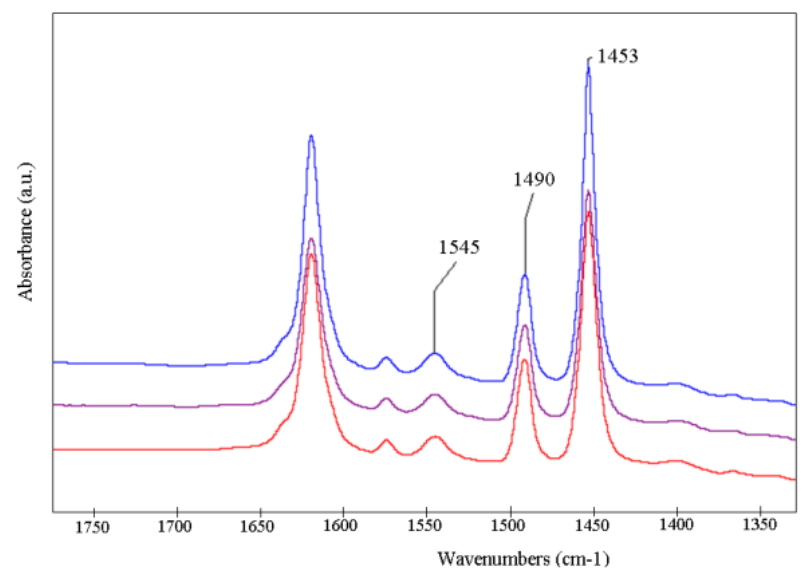

Figure 5. Difference IR spectra of the 5\%Fe@Y,6\%Fe@Y (red) and 8\%Fe@Y (violet) (blue) after pyridine desorption at $150^{\circ} \mathrm{C}$ for $15 \mathrm{~min}$ (spectra of the activated samples are subtracted, and spectra are normalized to pellet density of $10 \mathrm{mg} / \mathrm{cm}^{2}$ ).

The catalytic results for Ulvan hydrolysis in the presence of the investigated magnetic zeolites are summarized in Table 3. Ulvan is a water soluble sulfated polysaccharide that is hydrothermally stable at around $120-140{ }^{\circ} \mathrm{C}$. Above this temperature, it can easily release the sulfate groups and improve the thermohydrolysis process with the formation of low molecular weight products. In these conditions, the catalyst can increase the rate of the production of monomers and/or generate the formation of other sugars from produced monomers. On the other hand, the cleavage of the $\mathrm{C}-\mathrm{O}-\mathrm{C}$ glycosidic bond leads to the formation of degradation products, insoluble chars, and water soluble humins.

Table 3. The distribution of the ulvan hydrolysis products in the liquid phase, expressed as selectivity $(\%)$

\begin{tabular}{lllllllll}
\hline Sample & $Y_{\text {liquid }}$ & $X(\%)$ & Rha & Glu & HVA & LA+GA & Degradation & Ec (\%) \\
& $(\%)$ & & $(\%)$ & $(\%)$ & $(\%)$ & $(\%)$ & products (\%) &
\end{tabular}




\begin{tabular}{lllllllll}
\hline- & 47.0 & 71.0 & 13.3 & 9.2 & 5.8 & 10.3 & 61.4 & 66.2 \\
$5 \% \mathrm{Fe} @ \mathrm{Y}$ & 56.0 & 70.0 & - & - & 17.8 & 17.5 & 64.6 & 80.0 \\
$5 \% \mathrm{Fe} @ \mathrm{Y}^{[\mathrm{a}]}$ & 33.2 & 48.0 & 29.1 & 10.5 & 14.4 & 21.0 & 25.0 & 69.2 \\
$6 \% \mathrm{Fe} @ \mathrm{Y}$ & 68.2 & 71.3 & 5.5 & 8.6 & 23.8 & 30.8 & 31.3 & 86.0 \\
$8 \% \mathrm{Fe} @ \mathrm{Y}$ & 61.5 & 72.0 & 7.3 & 9.9 & 32.5 & 29.8 & 20.5 & 85.4 \\
\hline
\end{tabular}

Reaction conditions: $180^{\circ} \mathrm{C}, 6 \mathrm{~h}, 20 \mathrm{mg}$ of catalyst, $50 \mathrm{mg}$ of ulvan; [a] $-150^{\circ} \mathrm{C}$, Degradation products comprise succinic acid (5-15\%); other C4-C5 products: hydroxyacids (1-20\%), 2,4dihydroxyglutaric acid (1-15\%), other monosaccharides and glucuronic acid (1-5\%). Yliquidoverall yields in water-soluble products; $\mathrm{X}$ - Ulvan conversion; Ec - carbon efficiency indicating the selectivity to the water-soluble products. Rhamnose (Rha), Glucose (Glu), 4hydroxypentanoic acid (HVA), Lactic acid (LA) and Glycolic acid (GA)

The distribution of the reaction products depends on the reaction conditions and the concentration of ulvan and is the result of numerous competitive parallel reactions. The main constituent of ulvan is the sulfated glucurorhamnose unit providing glucuronic acid (GlcA) and rhamnose (Rha). Even though GlcA is one of the major monomers, its selectivity does not exceed $1-2 \%$. One possible explanation is that GlcA is degraded to a greater extent than Rha at high temperatures in the subcritical water conditions and at longer reaction times. ${ }^{22,}{ }^{23}$ Aida et al. ${ }^{24}$ indicated as degradation products of glucuronic acid several low molecular weight organic acids such as formic, acetic, lactic, glycolic, 2-hydroxybutyric, succinic and malic acid. The yield of Rha along the catalytic tests was also lower than expected, varying between $2 \%$ to $10.5 \%$. Different authors reported the recovery of almost all the Rha units from different types of Ulvan, at temperatures between $130^{\circ} \mathrm{C}-160^{\circ} \mathrm{C}$ and in the presence of solid acid catalysts as polyoxometalates $^{1}$ or ion-exchanging resins (Amberlyst 70). ${ }^{2}$ However, even more interesting, the small Rha selectivity in the present work is compensated by the formation of a high amount (35.6\%) of 4-hydroxyvaleric acid (HVA) and ( $\gamma$-hydroxyvaleric acid (GHV)) together with the 
low amount of a 3-hydroxypentanoic acid isomer (Scheme 1). The $\gamma$-hydroxyvaleric acid (GHV), also known as 4-methyl-GHB, is a designer drug related to $\gamma$-hydroxybutyric acid (GHB) ${ }^{25} \mathrm{HVA}$ is usually obtained as intermediate in the synthesis of biomass-derived valerolactone, through the hydrogenation of levulinic acid (LA) or hydrohymethylfurfural (HMF). In contrast to Tsubaki et al. ${ }^{1}$ no HMF was identified in the reaction products.

The sample 8\%Fe@Y with higher intensity for a-Fe reflection also displayed higher intensity for $\alpha-\mathrm{Fe}_{2} \mathrm{O}_{3}$ reflection. XRD patterns of $8 \% \mathrm{Fe} @ \mathrm{Y}$ catalyst after hydrolysis reaction are represented in Figure 6. The spent catalyst was separated from the reaction mixture with an external magnet, washed and dried. The cristallinity of the spent catalyst is preserved as there are no changes in XRD patterns.
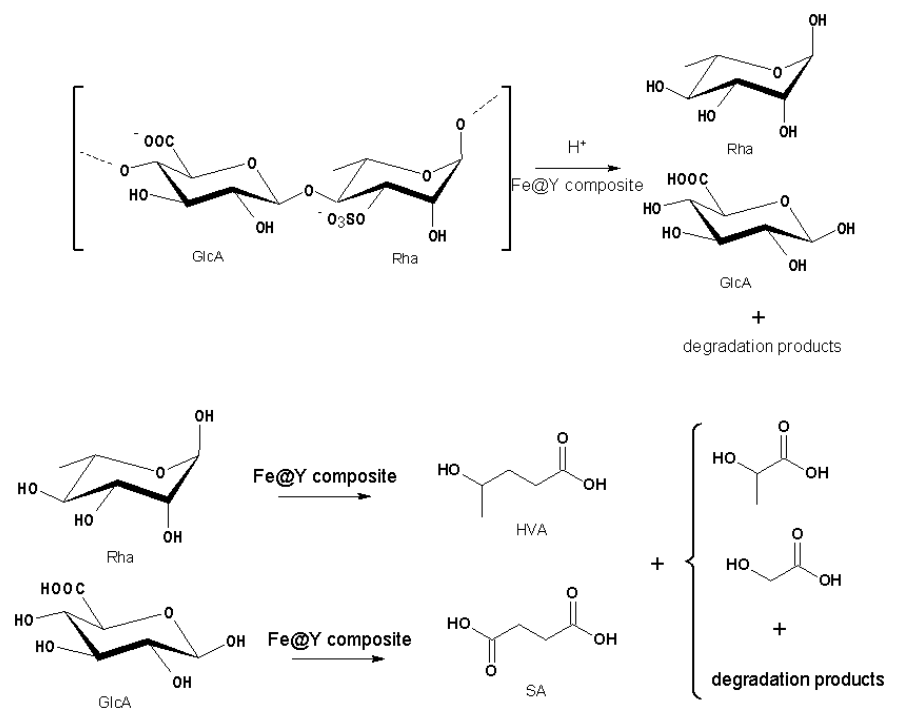

Scheme 1. Hydrolysis of Ulvan in the presence of Fe@Y composites; acidic species generated from sulfonic groups and water autoprotolysis provoke the further conversion of Rha and GlcA 


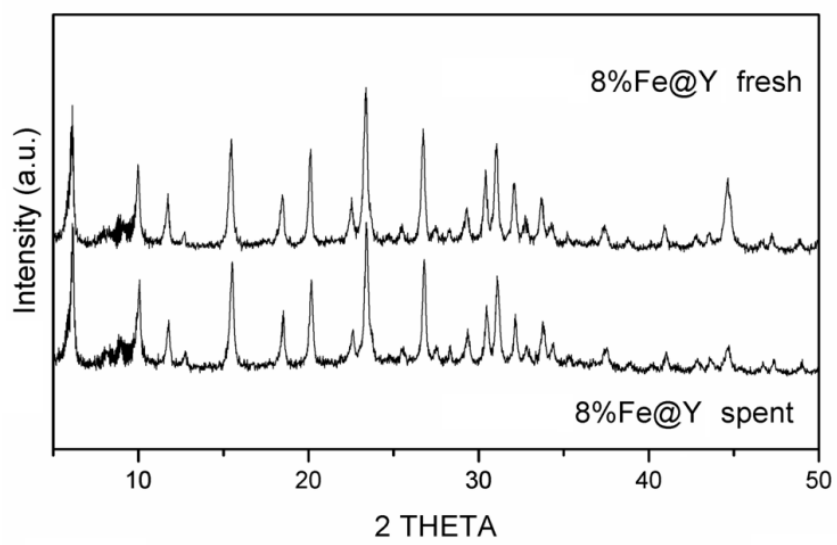

Figure 6. The XRD patterns for the 8\%Fe@Y sample before and after the hydrolysis of ulvan.

In order to confirm the correlation between the decrease of the selectivity to Rha in the favor to that of HVA, blank tests using mixtures of rhamnose (Rha) and glucose (Glu) as starting compounds were carried out (Table 4). Although these experiments did not consider the influence of all other products generated during the hydrolysis of Ulvan, they clearly confirmed the effect of the catalyst: its presence led to high amounts of glycolic acid (GA) along HVA and lactic acid (LA). Neither succinic acid (SA) nor 2,4-dihydroxyglutaric acid has been identified in blank tests (Table 4, entry 2), while their content in the Ulvan hydrolysates is noticeable. This fact may suggest, indeed, that these compounds are degradation products derived from glucuronic acid (GlcA). This idea and the fact that GlcA is more reactive was also confirmed by a blank test with GlcA only (Table 4, entry 5). Even in the absence of the catalyst GlcA is completely converted to lactic and glycolic acids and $10 \%$ to SA, the other products are represented by lactones. It was also observed that the hydrolysis of GlcA alone generates the highest amount of insoluble humins.

Table 4. Hydrolysis and oxidation of Rhamnose (Rha) and Glucose (Glu) 


\begin{tabular}{|c|c|c|c|c|}
\hline Sample & $\mathrm{X}(\%)$ & $\mathrm{Y}_{\mathrm{HVA}}(\%)$ & $\mathrm{Y}_{\mathrm{LA}+\mathrm{GA}}(\%)$ & Other products $(\%)$ \\
\hline No catalyst & 14.5 & 2.5 & 3.5 & 8.5 \\
\hline 8\%Fe@Y & 98.4 & 20.0 & 60.6 & 17.8 \\
\hline No catalyst ${ }^{[\mathrm{a}]}$ & 66.0 & - & 28.3 & $37.7 \%(3.14 \% \mathrm{SA})$ \\
\hline $8 \% \mathrm{Fe} @ \mathrm{Y}^{[\mathrm{a}]}$ & 82.3 & - & 36.6 & $45.7 \%(2.3 \% \mathrm{SA})$ \\
\hline No catalyst ${ }^{[\mathrm{b}]}$ & 100 & - & 87.0 & $13.0(10 \% \mathrm{SA})$ \\
\hline
\end{tabular}

Reaction conditions: $180^{\circ} \mathrm{C}$, $6 \mathrm{~h}$; Solution of Rha-5.2mg, Glu $-1.2 \mathrm{mg}$ in $5 \mathrm{~mL}$ of water. $10 \mathrm{mg}$ of catalyst. ${ }^{[\mathrm{a}]}$ - oxidation of Rha and Glu, $10 \mathrm{~atm} \mathrm{O}_{2}$; ${ }^{[\mathrm{b}]}$ - glucuronic acid GlcA

In the presence of molecular oxygen, the succinic acid (SA) is also formed with selectivities up to $43 \%$ (Table 5, entry 1). This is an appealing approach to obtain different target molecules with the same catalyst by varying the reaction conditions. The source of SA is not very clear as in blank tests a higher amount of SA derives from GlcA and a small part from the oxidation of Rha and Glu (Table 4, entries 3 and 4). It is interesting that during the oxidation Rha is isomerized to cyclic rhamnofuranose and derived lactones mostly represent the degradation products (Scheme 2).

Table 5. The distribution of the ulvan oxidation products in the liquid phase, expressed as selectivity $(\%)$

\begin{tabular}{lllllllll}
\hline Sample & $\begin{array}{l}\mathrm{Y}_{\text {liquid }} \\
(\%)\end{array}$ & $\mathrm{X}(\%)$ & Rha (\%) & Glu (\%) & SA (\%) & $\begin{array}{l}\text { LA+GA } \\
(\%)\end{array}$ & $\begin{array}{l}\text { Degradation } \\
\text { products }(\%)\end{array}$ & $\begin{array}{l}\text { Ec } \\
(\%)\end{array}$ \\
\hline $5 \% \mathrm{Fe} @ \mathrm{Y}$ & 50.2 & 69.0 & - & - & 43.8 & 17.6 & 38.6 & 72.7
\end{tabular}

Reaction conditions: $180^{\circ} \mathrm{C}, 6 \mathrm{~h}, 10 \mathrm{~atm} \mathrm{O}_{2}, 20 \mathrm{mg}$ of catalyst, 50mg of ulvan; Degradation products are represented by lactones. Yliquid-overall yields in water-soluble products; X Ulvan conversion; Ec - carbon efficiency indicating the selectivity to the water-soluble products; SA - succinic acid. Rhamnose (Rha), Glucose (Glu), Lactic acid (LA) and Glycolic acid (GA) 
Only minor differences were observed between the calcined and uncalcined catalysts in terms of the Ulvan conversion, selectivity to water soluble products, and carbon efficiency (Table 3). The only noticeable difference is in the product distribution. As previously reported, pure Lewis acids help the formation of triose sugars like LA and GA. ${ }^{26}$ On the other side, the presence of the Brønsted acidity promotes more complex isomerization and dehydration reactions. ${ }^{27}$ Also, some authors reported that the $\mathrm{NH}_{4}{ }^{+}$forms of zeolites are more active for reactions involving biomassderived molecules. The amount of Brønsted acid sites in $\mathrm{NH}_{4}{ }^{+}$form is higher for several types of zeolites. ${ }^{28}$ The ratio between Lewis and Brønsted acid sites is also important for the selectivity to some reactions.

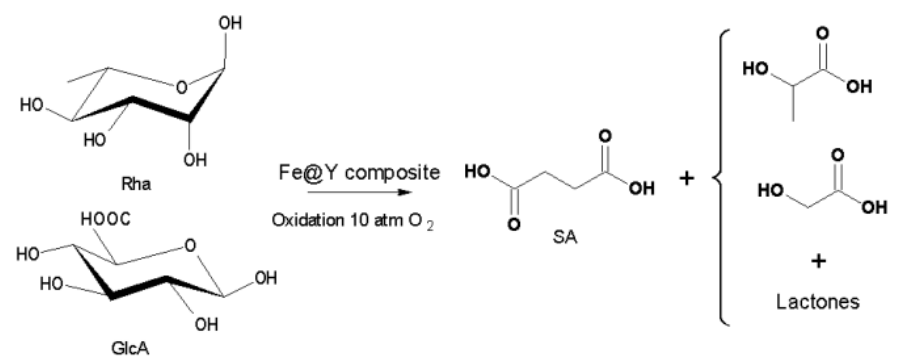

Scheme 2. Oxidation of Ulvan in the presence of Fe@Y composites.

As it was mentioned before, the degradation products arise from the different Ulvan constituents like glucuronic acid. Fe@Y composites present higher amounts of Lewis acid sites, although the Lewis acid centers may be suppressed under hydrothermal conditions. ${ }^{29}$

Variation of the concentration of Lewis acid centers and iron content in zeolites is represented in Figure 7. Regarding these features, there are no essential differences in prepared zeolites, but it can be observed a decrease of acidity with the increase of iron content. Although the iron nanoparticles have no catalytic activity, they can cover some of the active acid sites. ${ }^{30}$ 


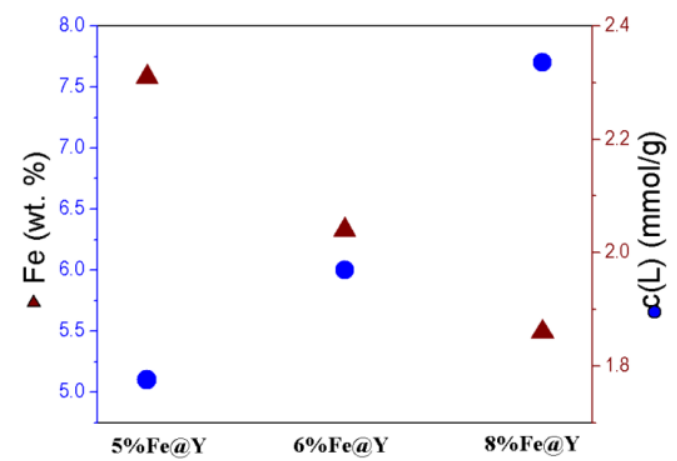

Figure 7. The relationship between the iron content in Fe@Y composites and the concentration of Lewis acid centers

These variations are enough to generate some differences in the rate of the transformation of monosaccharides, the conversion of Ulvan is maintained at the same level, helped by water autoprotolysis and sulfonic groups.

All Fe@Y composites were recycled for 10 times with no change in the catalytic performances after a simple magnetic separation and washing with water.

\section{CONCLUSIONS}

Three magnetic Fe@Y composite, which differs in small synthesis details, were successfully prepared and characterized. Activated catalysts contain mainly Lewis acid sites and small amounts of Brønsted acid sites. Hydrolysis of Ulvan on these catalysts occurs with the break of the C-O-C glycosidic bond and liberation of the main constituents as Rha and GlcA acid. In the presence of magnetic $\mathrm{NH}_{4}{ }^{+}$- zeolites, Rha and Glu can be further degraded to $\mathrm{C} 3$ products and hydroxycarboxylic acids, such as HVA. The selectivity can be completely changed to succinic acid (SA) in the presence of molecular oxygen. The presented magnetic composites and their application in marine biomass conversion deserve further exploration. 


\section{ASSOCIATED CONTENT}

\section{Supporting Information.}

The Supporting Information is available free of charge on the ACS Publications website. $\mathrm{N}_{2}$ sorption isotherms of $\mathrm{Fe} @ \mathrm{Y}$ composites.

\section{AUTHOR INFORMATION}

\section{Corresponding Author}

*Vassilios Roussis: roussis@pharm.uoa.gr, Valentin Valtchev: valentin.valtchev@ensicaen.fr, Vasile I. Parvulescu: vasile.parvulescu@chimie.unibuc.ro

\section{Author Contributions}

The manuscript was written through contributions of all authors. All authors have given approval to the final version of the manuscript.

\section{ACKNOWLEDGMENT}

The work on this paper was supported by the Government of Romania, Ministry of Research and Innovation, Projects PN-III-P4-ID-PCCF-2016-0688; PN-III-P4-ID-PCE-2016-0146 and PN-IIIP1-1.2-PCCDI-2017-0541.

\section{REFERENCES}

[1] Tsubaki, S.; Oono, K.; Hiraoka, M.; Ueda, T.; Onda, A.; Yanagisawa, K.; Azuma, J. Green Chem. 2014, 16, 2227-2233. 
[2] Onda, A.; Onda, S.; Koike, M.; Yanagisawa, K.; Tsubaki, S.; Hiraoka, M.; ChemCatChem 2017, 9, 2638-2641.

[3] Gürbüz, E. I.; Gallo, J. M.; Alonso, D. M.; Wettstein, S. G.; Lim, W. Y.; Dumesic, J. A. Angew. Chem. Int. Ed. Engl. 2013, 52, 1270-1274.

[4] Pezoa-Conte, R.; Leyton, A.; Baccini, A.; Ravanal, M. C.; Mäki-Arvela, P.; Grénman, H.; Xu, C.; Willför, S.; Lienqueo, M. E.; Mikkola, J. P. Bioenergy Research 2017, 10, 915-928.

[5] Ennaert, T.; Van Aelst, J.; Dijkmans, J.; De Clercq, R.; Schutyser, W.; Dusselier, M.; Verboekend, D.; Sels, B. F. Chem. Soc. Rev. 2016, 45, 584-611.

[6] He, Y.; Hoff, T. C.; Emdadi, L.; Wu, Y.; Bouraima, J.; Liu, D. Catal. Sci. Technol. 2014, 4, 3064-3073.

[7] Oh, S. C.; Nguyendo, T.; He,Y.; Filie, A.; Wu, Y.; Tran, D. T.; Lee, I. C.; Liu, D. Catal. Sci. Technol. 2017, 7, 1153-1166.

[8] Karimi, B.; Mansouri, F.; Mirzaei, H. M. ChemCatChem 2015, 7, 1736-1789.

[9] Kuncser, V.; Coman, S. M.; Kemnitz, E.; Parvulescu, V. I. J. Appl. Phys. 2015, 117, $17 \mathrm{D} 724$.

[10] Jorge, E. Y. C.; Lima, T. de M.; Lima, C. G. S.; Marchini, L.; Castelblanco, W. N.; Rivera, D. G.; Urquieta-González, E. A.; Varma, R. S.; Paixão, M. W. Green Chem. 2017, 19, 3856-3868.

[11] Lima, T. de M.; Lima, C. G. S.; Rathi, A. K.; Gawande, M. B.; Tucek, J.; UrquietaGonzález, E. A.; Zbořil, R.; Paixão, M. W.; Varma, R. S. Green Chem. 2016, 18, 5586-5593. 
[12] Subramanian, V.; Cheng, K.; Lancelot, Ch.; Heyte, S.; Paul, S.; Moldovan, S.; Ersen, O.; Marinova, M.; Ordomsky, V.; Kodhakov, A.Y. ACS Catal. 2016, 6, 1785-1792.

[13] Robson, H., (ed.) Verified Syntheses of Zeolitic Materials, $2^{\text {nd }}$ Revised Edition, Elsevier: Amsterdam, 2001, pp. 156.

[14] Lippens, B. C.; de Boer, J. H. J. Catal. 1965, 4, 319-323.

[15] Nesterenko, N. S.; Thibault-Starzyk, F.; Montouilliout, V.; Yushchenko, V. V.; Fernandez, C.; Gilson, J.-P.; Fajula, F.; Ivanova, I. I. Kinet. Catal. 2006, 47, 40-48.

[16] Thibault-Starzyk, F.; Gil, B.; Aiello, S.; Chevreau, T.; Gilson, J.-P. MicroporousMesoporous Mater. 2004, 67, 107-112.

[17] Dubois, M. K.; Gilles, A.; Hamilton, J. K.; Rebers, P. A.; Smith, F. Anal. Chem. 1956, $28,350-356$.

[18] Blumenkrantz, N.; Asboe-Hansen, G. Anal. Biochem. 1973, 54, 484-489.

[19] Quemener, B.; Thibault, J. F. Carbohydr. Res. 1990, 206, 277-287.

[20] Sassaki, G. L.; Souza, L. M.; Serrato, R. V.; Cipriani, T. R.; Gorin, P. A. J. J. Chromatogr. A 2008, 1208, 215-222.

[21] Kawai, Y.; Seno, N.; Anno, K. Anal. Biochem. 1969, 32, 314-321.

[22] Usuki, C.; Kimura, Y.; Adachi, S. Chem. Eng. Technol. 2008, 1, 133-137.

[23] Wang, R.; Neoh, T. L.; Kobayashi, T.; Miyake, Y.; Hosoda, A.; Taniguchi, H.; Adachi, S. Biosci. Biotechnol. Biochem. 2010, 74, 601-605. 
[24] Aida, T. M.; Yamagata, T.; Abe, C.; Kawanami, H.; Watanabe, M.; Smith Jr., R. L. J. Supercrit. Fluids 2012, 65, 39-44.

[25] Carter, L. P.; Chen, W.; Wu, H.; Mehta, A. K.; Hernandez, R. J.; Ticku, M. K.; Coop, A.; Koek, W.; France, C. P. Drug Alcohol Depen. 2005, 78, 91-99.

[26] West, R. M.; Holm, M. S.; Saravanamurugan, S.; Xiong, J.; Beversdorf, Z.; Taarning, E.; Christensen, C. H. J. Catal. 2010, 269, 122-130.

[27] Saravanamurugan, S.; Riisager, A. ChemCatChem 2013, 5, 1754-1757.

[19] Lanzafamea, P.; Barberaa, K.; Papanikolaoua, G.; Perathonera, S.; Centia, G.; Migliorib, M.; Catizzone, E.; Giordano, G. Catal. Today 2018, 304, 97-102.

[20] Román-Leshkov, Y.; Davis, M. E. ACS Catal. 2011, 1, 1566-1580.

[30] Pescarmona, P. P.; Gagea, B. C.; Van der Aa, P.; Jacobs, P. A.; Martens, J. A. Catal. Today 2011, 159, 120-125. 


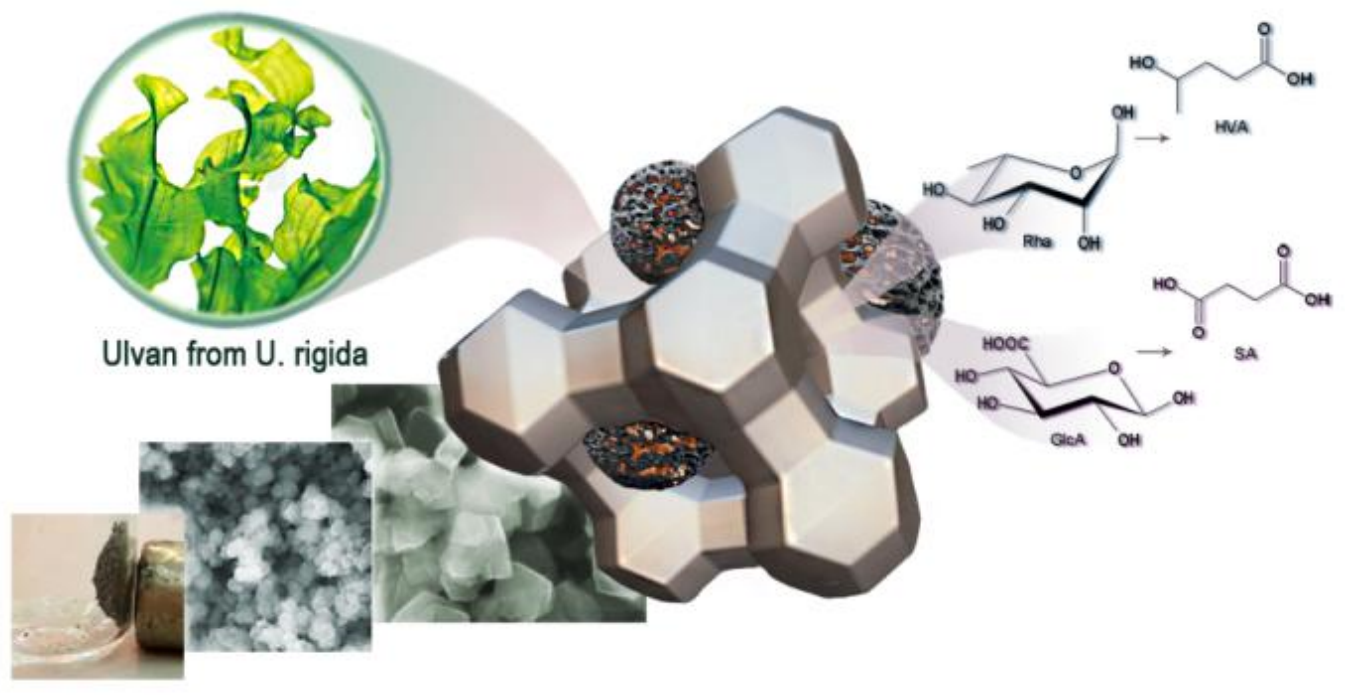

HAL pre-

prints_1 